\title{
Local tree knowledge can fast-track agroforestry recommendations for coffee smallholders along a climate gradient in Mount Elgon, Uganda
}

\author{
Gil Gram • Philippe Vaast · Just van der Wolf • Laurence Jassogne
}

Received: 6 October 2016/Accepted: 27 July 2017/Published online: 31 July 2017

(C) The Author(s) 2017. This article is an open access publication

\begin{abstract}
Arabica coffee (Coffea arabica) is economically important for many smallholder farmers in the Mount Elgon region of East Uganda, but its production is increasingly threatened by climate change. However, ecosystem services (ES) provided by companion trees in coffee agroforestry systems (AFS) can help farmers adapt to climate change. The objectives of this research were to develop agroforestry species recommendations and tailor these to the farmers' needs and local context, taking into consideration gender. Local knowledge of agroforestry species and ES preferences was collected through farmer interviews and rankings. Using the
\end{abstract}

G. Gram $(\bowtie) \cdot$ J. van der Wolf · L. Jassogne

International Institute of Tropical Agriculture (IITA), 15

Naguru East Road, P.O. BOX 7878, Kampala, Uganda

e-mail: g.gram@cgiar.org

J. van der Wolf

e-mail: justvanderwolf@gmail.com

L. Jassogne

e-mail: 1.jassogne@cgiar.org

P. Vaast

Centre de coopération Internationale en Recherche

Agronomique pour le Développement (CIRAD), UMR

Eco\&Sols, 2 place Viala, 34060 Montpellier Cedex 2,

France

e-mail: philippe.vaast@cirad.fr

P. Vaast

World Agroforestry Centre (ICRAF), United Nations

Avenue, Gigiri, P. O. Box 30677, Nairobi 00100, Kenya
Bradley-Terry approach, analysis was done along an altitudinal gradient in order to study different climate change scenarios for coffee suitability. Farmers had different needs in terms of ES and tree species at different altitudes, e.g. at low altitude they need a relatively larger set of ES to sustain their coffee production and livelihood. Local knowledge is found to be gender blind as no differences were observed in the rankings of species and ES by men and women. Ranking species by ES and ranking ES by preference is a useful method to help scientists and extension agents to use local knowledge for the development of recommendations on companion trees in AFS for smallholder farmers.

Keywords Climate change - Ecosystem services . Smallholder farmer ranking · Famer perceptions . Local knowledge $\cdot$ Shade trees

\section{Introduction}

Coffee is one of the major cash crops for many smallholder farmers in the East African highlands. In Uganda, coffee is the most important export crop with $90 \%$ produced by farm households with less than three hectares of land. In fact, Uganda is the second largest coffee producer in Africa, accounting for approximately $2.5 \%$ of global coffee production of predominantly Robusta coffee (Coffea canephora) (Chiputwa 
et al. 2015). Still, Arabica coffee (C. arabica) is of significant economic value for Mount Elgon, Uganda's larget Arabica growing region in the East (Van Asten et al. 2011).

The performance of Arabica coffee is strongly influenced by climatic variability, and hence particularly sensitive to climate change (Campbell et al. 2014; Craparo et al. 2015; Davis et al. 2012; Vaast et al. 2005). At temperatures higher than the optimum range for Arabica $\left(18-23{ }^{\circ} \mathrm{C}\right)$, coffee growth is reduced while development and ripening of berry pulp are accelerated, often leading to the loss of beverage quality due to an incomplete bean filling (Davis et al. 2012; Vaast et al. 2006). Drought and high temperatures are the major climatic limitations for Arabica coffee production in East Africa. These climatic conditions are expected to be more frequent with climate change, which already impacted Ugandan coffee sector, and is reducing the area suitable for coffee production (Bunn et al. 2015b; Jaramillo et al. 2011). With coffee-growing altitudes ranging from 1000 masl to over 2000 masl, the Mt. Elgon region can be used as a field laboratory to anticipate climate change and evaluate its impact on coffee, as suitable areas will shift upwards with time (Bunn et al. 2015a, b; Läderach et al. 2011).

In Uganda, the vast majority of coffee is grown in agroforestry systems (AFS) with significant presence of trees and bananas (Van Asten et al. 2012). These systems provide a range of ecosystem services (ES) at plot, farm and landscape levels. The ES can be economical (e.g. timber, fuelwood, fruit, and high value niche markets) or environmental (e.g. biodiversity conservation, carbon sequestration and buffering changes in temperature and precipitation), and can enhance the sustainability and resilience of agricultural systems (Cerdán et al. 2012; Nzeyimana et al. 2013; Perfecto et al. 2007; De Souza et al. 2012). However, the extent to which ES are beneficial for coffee productivity depend on the local environment, livelihood strategies of producers, local market conditions (e.g. coffee prices and local wages), and management practices (e.g. use of external inputs) (Van Asten et al. 2010; Cerdán et al. 2012).

As trees in coffee AFS provide a range of ES that are not directly related to coffee production, they are usually referred to as companion trees and increasingly promoted as a "climate-smart" practice, improving the resilience of coffee production by creating favourable microclimate conditions, as well as improving soil health (Van Asten et al. 2010; Beer et al. 1998; Campbell et al. 2014; Nzeyimana et al. 2013; Vaast et al. 2006). Trees in AFS increase the biodiversity that enhances biological control of P\&D (Staver et al. 2001; Bos et al. 2007; Perfecto et al. 2007; Tscharntke et al. 2011). The role of companion trees in climate change adaptation and mitigation needs to be better documented and compared to monocropping systems (Cerdán et al. 2012; Harvey et al. 2014; Rahn et al. 2013; Vaast et al. 2005, 2006). Research on coffee companion trees has been mainly concentrated in Latin America and India, and mostly on their effects on coffee. More research is needed to provide site-specific insights in the benefits and constraints for East Africa as well as to better address the livelihood needs of coffee communities. In this regard, the use of local knowledge on agroforestry can be helpful whilst avoiding expensive and timeconsuming trials.

Local tree knowledge plays an important role in traditional agroforestry design, because farmers customise their AFS according to their knowledge and preference of trees and ES that these trees are providing (Cerdán et al. 2012; Valencia et al. 2015). Preferences and management decisions regarding companion trees can be gender-specific, especially with coffee, as it is traditionally a men's cash crop (Kasente et al. 2002; Kelemen et al. 2015; Kiptot et al. 2014; Kiptot 2015). Yet, according to Lecoutere and Jassogne (2016) and Villamor et al. (2014), literature on gender in coffee systems is scarce, and hence there is a need to fill this gap, particularly on local tree knowledge. Local knowledge is, as opposed to indigenous knowledge, not geographically or ethnically specific and can be similar at different locations if within similar agroecological context (Sinclair and Joshi 2000). While Albertin and Nair (2004) and Soto-Pinto et al. (2007) have reported on local knowledge on tree diversity in coffee AFS, it is only in recent years that research has documented on both local knowledge and ES provision in coffee AFS and landscapes (Cerdán et al. 2012; Lamond et al. 2016; Smith-Dumont et al. in press).

The objectives of this research were (1) to develop agroforestry species recommendations along an altitude and climate gradient, using local tree knowledge on ES provision, and (2) to align these 
recommendations to farmers' needs by ranking a group of key ES according to farmers' preferences and livelihood strategies. Potential differences between men and women were taken into consideration for both objectives.

\section{Materials and methods}

Study area

The research was carried out in the Mt. Elgon region of Eastern Uganda in the districts Bulambuli and Kapchorwa that include the eight sub-counties: Bulegeni, Bumugibole, Lusha, Masira, Simu, Sisiyi, Buginyanya and Kaserem. The area was subdivided into three altitude zones, i.e. the low zone ( $<1400$ masl), the mid zone (1400-1700 masl) and the high zone $(>1700$ masl). The selected farmers are situated within an area of $210 \mathrm{~km}^{2}$ (Fig. 1 (Liebig et al. 2016)).

The mean annual rainfall in the study area ranges from 1200 to 1400 and $1800 \mathrm{~mm}$ and the mean annual temperatures are 23,21 and $18{ }^{\circ} \mathrm{C}$, at respectively low, mid and high altitudes (Hijmans et al. 2005). Although there is a significant local climate variability, Mbogga (2012) suggested that the Mt. Elgon region had experienced an increase in temperatures between 0.4 and $1.2{ }^{\circ} \mathrm{C}$ when comparing the 2001-2011 period to the 1961-1990 period. Furthermore, dry seasons are getting longer, causing crop water stress, particularly at lower altitudes (Bunn et al. 2015b; Mbogga 2012).

Due to the relatively high population density of approximately 250 and 300 inhabitants per $\mathrm{km}^{2}$ for Bulambuli and Kapchorwa, respectively (Uganda Bureau of Statistics 2016), the landscape is mainly made of smallholder farms $(<2$ ha) with generally intensive and mixed coffee (C. arabica) $\mathrm{x}$ banana (Musa spp. AAA-EA) based agricultural systems. Coffee is grown under varying levels of shade provided by various companion tree species and banana. Traditional East African Arabica coffee varieties are predominantly grown, including SL 14, SL 28 and Nyasaland (locally known as Bugisu Local). Coffee productivity has been shown to be substantially lower than its potential due to low soil fertility, high P\&D pressure and poor land and coffee tree management practices (Wairegi and Van Asten 2010; Wang et al. 2015).
Surveys and data collection

In total, 301 farmers were selected from 196 farms, including 183 men (M) and 118 women (F). Most of the women (105) were from the same households as the men that were interviewed. For the low, mid and high altitude zones there were 103 farmers $(63 \mathrm{M}, 40$ F), 97 farmers (61 M, 36 F) and 101 farmers (59 M, 42 F), respectively. Questionnaires were digitised and used together with plasticised ES pictograms and tree species fact/technical sheets with clear recognizable pictures of the tree shape, mean features of crown, bark, fruits, and leaves.

For each altitude zone, the 20 most abundant species were selected for the ranking exercises, covering more than $98 \%$ of the recorded trees. At low and mid altitude, this yielded 23 and 22 species respectively, as the 20th place was shared by several species. At high altitude, only 19 species were recorded and hence all were selected. Since coffee is predominantly intercropped with banana, also providing shade, it was included in the ranking exercise along with tree species. Of those 20 species, the farmers were asked to identify the 10 species they know best for the ranking exercise. The authors considered based on expert knowledge that people can rank to a maximum of 10 items, without losing ranking quality.

Farmers were asked to identify ES that they attribute to companion trees on their coffee plot. Then, considering the time span of interviews and farmer availability, the 12 most mentioned ES were selected and grouped into two categories (Table 1). These were based on the Millennium Ecosystem Assessment classification of Leemans and de Groot (2003), but adapted to the context of this specific study. i.e., the regulating ES were subcategorised into microclimate (buffering temperature extremes and conserving soil moisture), soil fertility (producing mulch and controlling erosion), P\&D (decreasing incidence of White Coffee Stem Borer (WCSB) and Coffee Leaf Rust (CLR)), and weed control. The provisioning ES were subcategorised into coffee production (yield improvement/stabilisation and coffee tree life expectancy increase) and tree products (food, timber, and fuelwood). For the latter subcategory, only relevant tree species were analysed (e.g. only food-providing trees for the ES 'food'). The focus on WCSB and CLR is based on the fact that they are the most important $\mathrm{P} \& \mathrm{D}$ problems for the present 


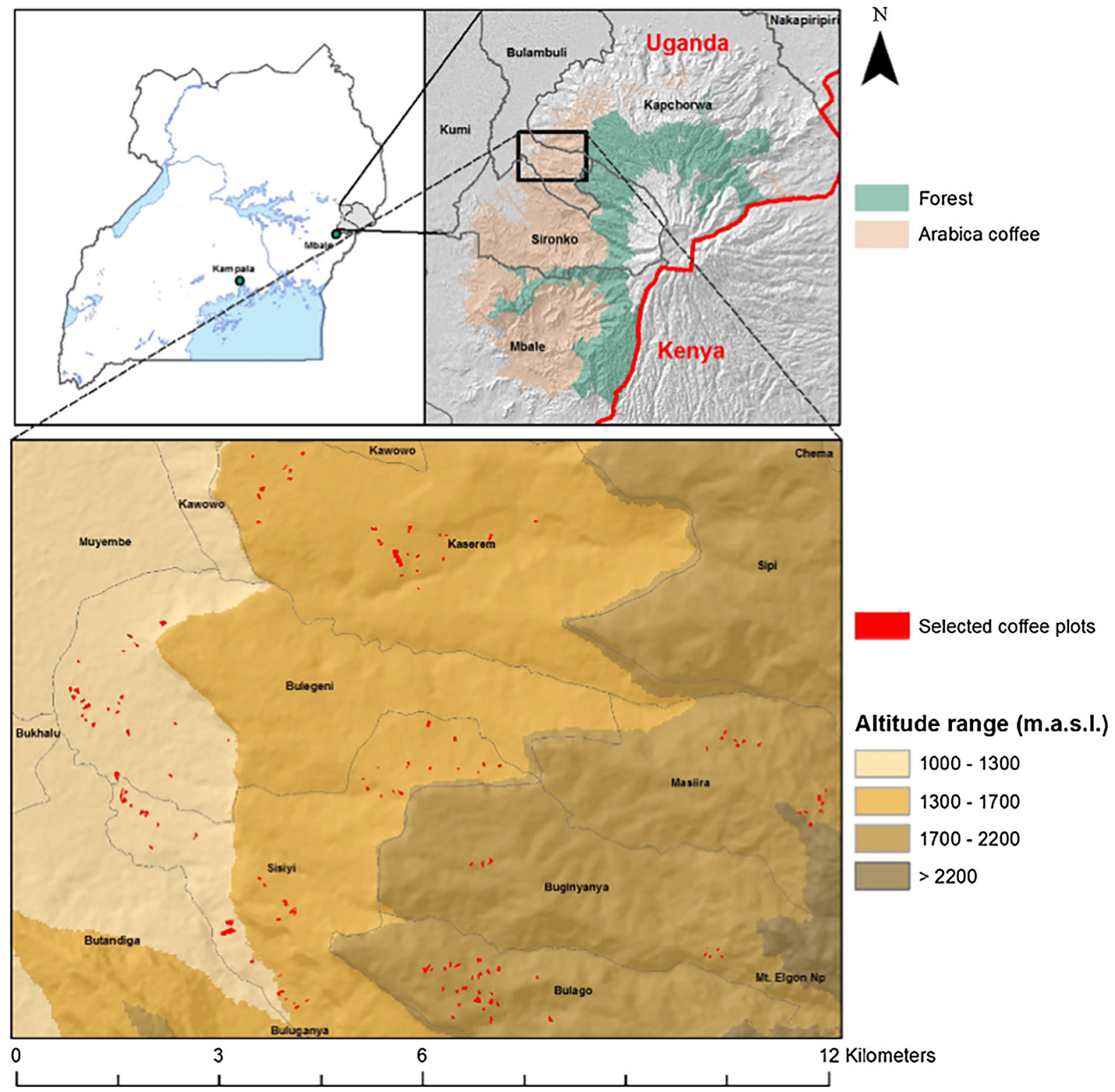

Fig. 1 Location of the study area within Uganda, Mount Elgon area (top left), districts of study area (Bulambuli, Kapchorwa) (top right), and study site with indication of three altitude zones

coffee systems over all three altitude zones in Mount Elgon (Liebig et al. 2016).

The questionnaires consisted of three questions: (1) identify 10 tree species that you know best out of the top 20 most abundant species at your specific altitude, (2) rank these species according to each of the $12 \mathrm{ES}$ (tree species with the same rank were allowed, i.e. ties), and (3) rank the 12 ES according to importance for your livelihood. (determined by means of cluster analysis) and sample plots (Liebig et al. 2016)

Ranking tree species and ecosystem services with the Bradley Terry model

A ranking is a relationship between a set of items such that, for any two items, the first is either 'ranked higher than', 'ranked lower than' or 'ranked equal to' the second. Ranking should not be confused with rating, where the items are scored with absolute values on a scale for example from 1 (bad) to 5 (good). In ranking 
Table 1 Twelve ecosystem services (ES) attributed to companion trees by farmers are grouped into two MEA categories and six subcategories: microclimate (buffering temperature extremes and conserving soil moisture), soil fertility (producing mulch and controlling erosion), pests and diseases control (decreasing incidence of White Coffee Stem Borer (WCSB) and Coffee Leaf Rust (CLR)), weed control (weed), coffee production (yield improvement/stabilisation and coffee tree life expectancy increase) and tree products (food, timber, fuelwood)

\begin{tabular}{lllllll}
\hline Regulating ES & & & & & Provisioning ES \\
\cline { 1 - 1 } Microclimate & Soil fertility & Pests and diseases & Weed control & & Coffee production & Tree products \\
\hline Temperature & Mulch & WCSB & Weed & & Life expectancy & Food \\
Soil moisture & Erosion & CLR & & Yield & Timber \\
& & & & & Fuelwood \\
\hline
\end{tabular}

however, items are scored relative to the other items, hence their scores have no meaning out of the context. Ranking is therefore a subjective evaluation that is useful in pair-wise comparisons.

There are some well-known non-parametric statistical methods based on ranks, i.e. the KruskallWallace test and Friedman test. However, they are not suitable in the context of this study as they do not account for ties in partial rankings (items have the same ranking score). For this reason, the Bradley and Terry (1952) approach was used to analyse the ranking data of tree species and ES. Hence, the data was analysed in $\mathrm{R}$ ( $\mathrm{R}$ Core Team 2015) using the BradleyTerry2 package (Turner and Firth 2012) and three other $\mathrm{R}$ functions as explained Van der Wolf et al. (2016).

The Bradley Terry analysis yielded ranking estimates from each individual farmer and used those to create one combined ranking for all the farmers. The analysis also yielded p-values from Wald comparison tests to indicate how significantly different these ranking estimates were from each other. As argued by Van der Wolf et al. (2016), the confidence intervals could vary quite significantly between tree species so they were plotted not solely based on the order of decreasing ranking estimates, but on a combination that includes both the estimate and the size of the confidence interval.

For the sake of developing recommendations and in order to make the interpretation and comparisons of rankings easier and visual, a decision rule was used to group and label tree species based on their ranking estimates. A first group was created starting with the highest ranked species. The next species was included in the group if its ranking was not significantly different from the first species in that group. If there was a significant difference, a new group was created after which the procedure was repeated. The first two groups were then labelled as 'high', groups three and four as 'medium', and the remaining groups as 'low'. All species below the upper four groups were put into a 'low' category as their interest as recommended species mainly lies in the upper part of the rankings. Combining groups was necessary to obtain a more or less even spread of differently labelled species, as illustrated in Fig. 2.

\section{Results and discussion}

Tree species ranking by ecosystem service and altitude

From the interviews, it appeared that the vast majority of farmers did not have sufficient knowledge on interactions between tree species and WCSB or CLR, respectively ranked by only 22 and $39 \%$ of them. Consequently, tree species ranking analysis for those P\&D was done with all altitudes combined and could not be presented in Fig. 3 together with the other 10 ES. This analysis showed that only two significantly different groups of ranking estimates were identified for both WCSB and CLR, whereby Cordia africana, A. coriaria, and Ficus mucuso represented the first group (labelled as 'high'), and all the others species were found in the second group (labelled as 'medium'). This means that except for these three highest ranked species, there was no consensus in the rankings of the other species for these two locally important P\&D and confirms that local knowledge about specific companion tree species and their relationships to coffee $P \& D$ dynamics is scarce as explained by Liebig et al. (2016). 


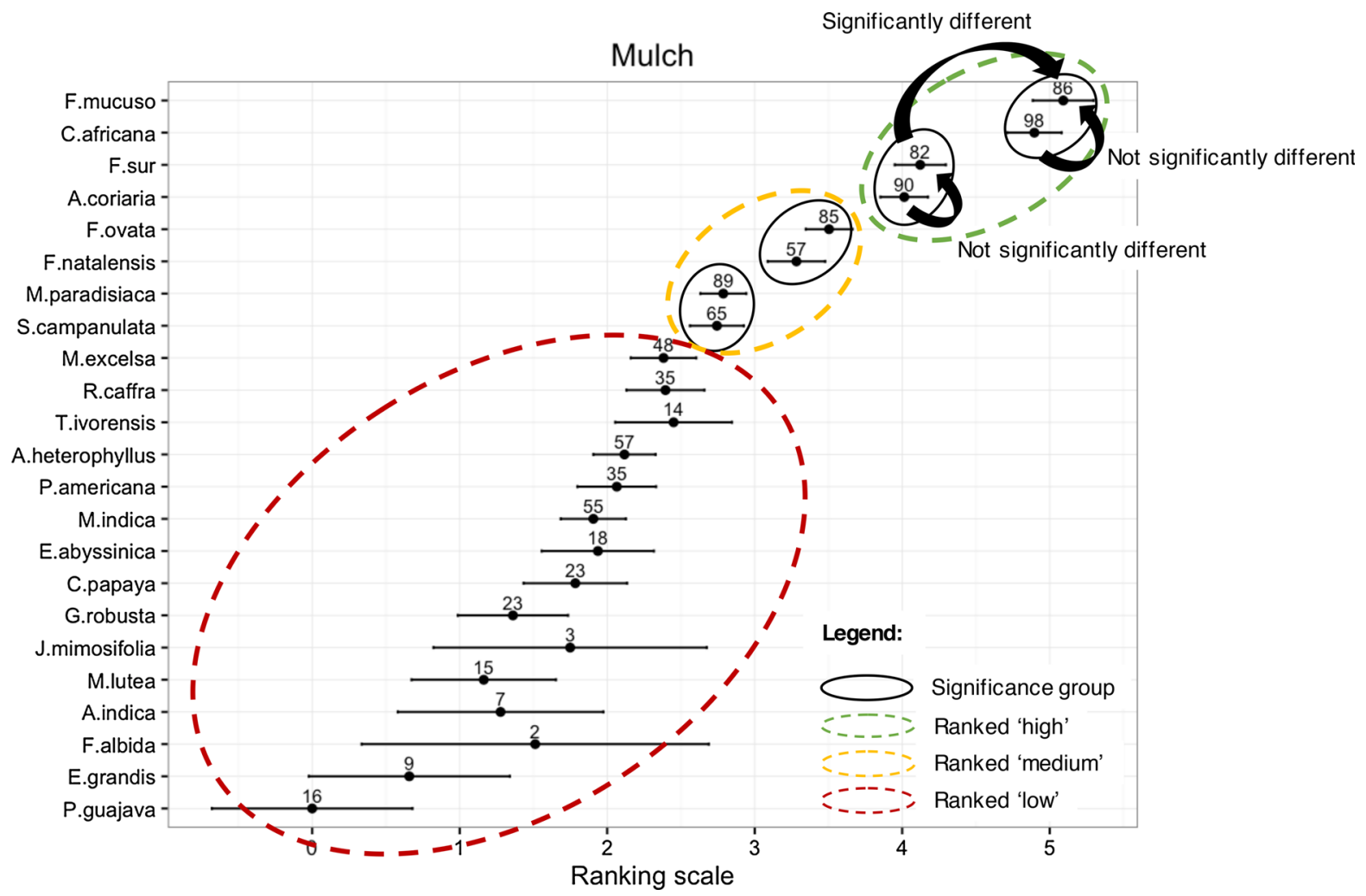

Fig. 2 The ranking result of tree species for the ecosystem service mulch at low altitude as an illustration of how the ranking estimates of tree species were grouped and labelled in order to make the interpretation and comparisons easier and visual. The estimates were annotated with the number of farmers

Cordia africana was exceptionally well ranked for all altitudes and ES (except food) and was followed by the four Ficus species and A. coriaria. Literature confirms that some of these species are well known for providing several of the presently targeted ES (Meunier et al. 2010; Ndenecho and Lambi 2010; Orwa et al. 2009). Musa spp. were ranked from medium to low for all ES other than food, which illustrates that farmers deliberately intercrop coffee and banana very commonly in the very densely populated area of Southern Uganda for food security reasons (Van Asten et al. 2011; Ellis and Bahiigwa 2003). Farmers need to secure food for their households irrespective of any other potential ecosystem service or disservice of banana compared to companion trees.

Overall, different categories of tree species can be identified based on the ranking results. Species such as $C$. africana and $F$. mucuso were ranked high, irrespective of altitude and ES. Likewise, Spathodea ranking that species for that specific ecosystem service. The confidence intervals can be seen as an indicator of the frequency and the homogeneity with which farmers have ranked tree species

campanulata and Psidium guajava were predominantly ranked medium and low, respectively. Then there were species whose ranking performance is dependent on altitude or ES. For instance, Ficus natalensis, Ficus ovata and Terminalia ivorensis were generally ranked higher at high altitudes and lower at low altitudes, whereas it was the opposite for Aleurites molucana and Faidherbia albida. Species that were ranked depending on the ES, were highly ranked only for specific ES. However, their rankings were also dependent on altitude to some extent. For example, Musa spp. were consistently ranked high for food, while they were ranked low for the other ES at low altitude. Similarly, Milicia excelsa was only ranked high for fuelwood and timber at mid and high altitudes, but ranked low for fuelwood and all other ES at low altitude. Finally, Eucalyptus grandis was consistently ranked low for all ES except for fuelwood and timber, but also ranked low for these at low altitude. 


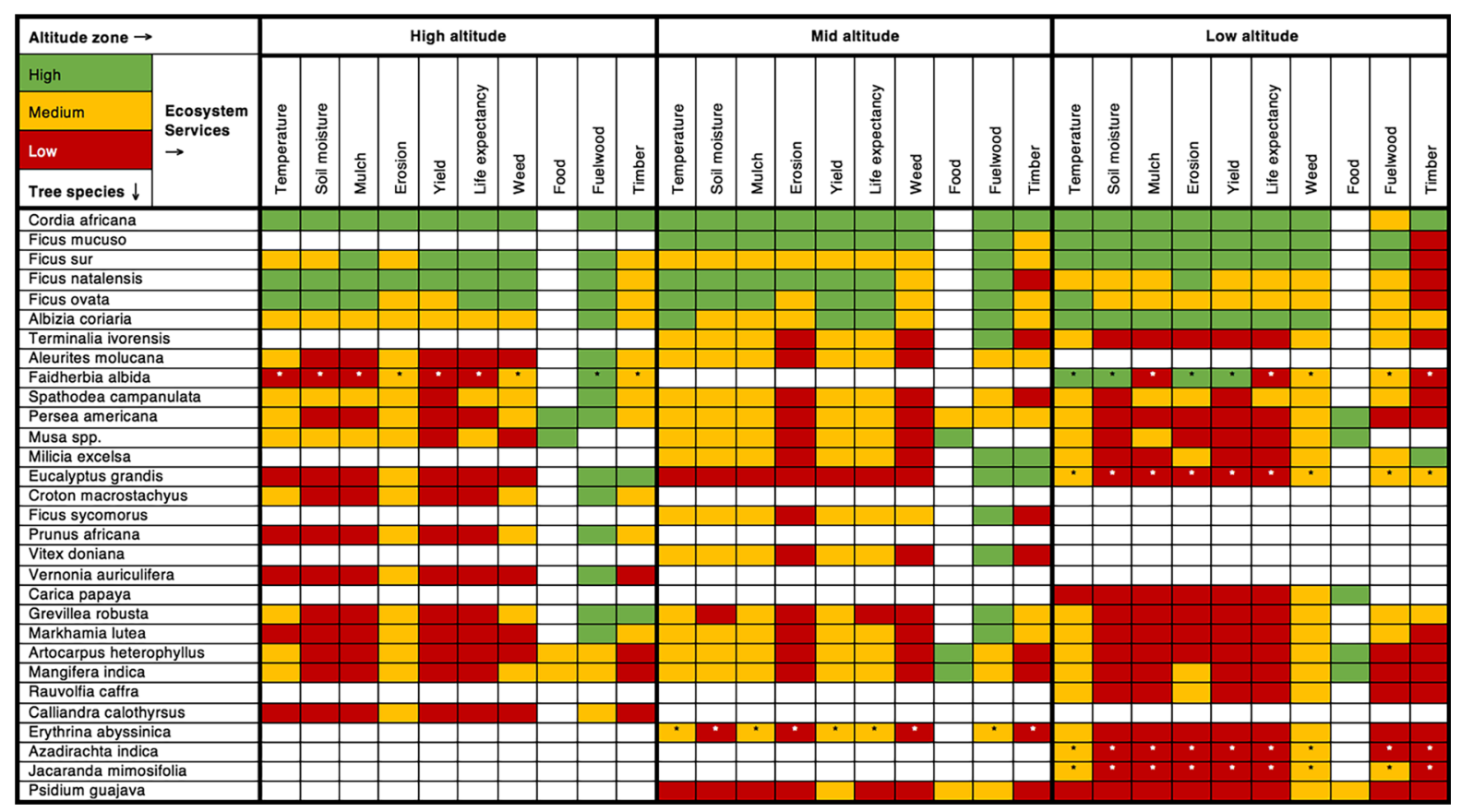

Fig. 3 Overview of the rankings of 30 tree species by ten ecosystem services (ES) and by three altitude zones. Hence, the columns are a representation of the species ranking for a specific ES at a specific altitude. The species were given labels based on their relative position within the ranking. The first two groups of species that were ranked highest and whose position was

There are biophysical factors (e.g. climate, soil characteristics) and socio-economic factors (e.g. distance to markets, population pressure) that influence the farmer's appreciation and ranking of a companion tree species in different contexts (Lamond et al. 2016). These factors have not been identified and studied as such, but the authors recommend taking them into account in further ranking research. Under the widely accepted assumption that climate is one of the determining factors, it is expected that the aforementioned tree species and their respective ES provision will play different but complementary roles in climate change adaptation. It is suggested that species that were ranked high for all altitudes, are climate change resilient. Species whose ranking performance is altitude dependent and that were currently ranked high at low altitude, can be useful in the future for adaptation at mid to high altitudes. On the other hand, those species that were ranked low at low altitudes but high at higher altitude, will probably become decreasingly suitable in a changing climate. significantly different were labelled as 'high', the next two significantly lower ranked groups were labelled as 'medium', and the rest of the lower ranked species were labelled as "low". * means that that the tree was selected and ranked by fewer than ten farmers so its ranking was considered less reliable. Blanks mean there was no ranking done for that specific tree and ES

Although biodiversity conservation was not included in the list of ES selected by farmers in the present study, it is still important to take into account when recommending (companion) tree species in general. In the present case, Prunus africana and $M$. excelsa were rated by the IUCN as 'vulnerable' and 'near threatened' respectively (World Conservation Monitoring Centre 1998a, b). As such, tree species recommendations could become part of a conservation strategy for Mt. Elgon region.

\section{Ecosystem service ranking by altitude}

The ES were ranked according to the farmer's preference. The ES rankings were grouped as already done for the species rankings in Figs. 2 and 3, but with a slightly different labelling. More specifically, only the first group was labelled as 'high', the second as 'medium', and the remaining groups as 'low' (Fig. 4). As there are only 12 ES and 3-7 significance groups, it was not necessary to combine groups in order to obtain a more or less even spread of differently labelled ES. 
Figure 4 shows that the ES rankings at higher altitude are more differentiated as opposed to those at lower altitude with seven, five, and three distinct groups, respectively. In other words, farmers at high altitude were more in agreement to distinguish the ES than the farmers at low altitude.

It was also observed that the relative preference for ES changed with altitude. Whereas at high altitude soil fertility improvement (mulch and erosion) was preferred over microclimate regulation (temperature and soil moisture) and both were preferred over coffee production (yield and life expectancy), the relative importance of the latter two (microclimate and production) increased towards lower altitudes. Hence, all three ecosystem functions were equally preferred at low altitude (Fig. 5). Bunn et al. (2015b) and Läderach et al. (2013) reported that climate change is affecting Arabica coffee most importantly at low altitude, due to higher temperatures, prolonged drought and thus more exposure to water and heat stresses. As such it is hypothesised that low-altitude farmers need a wider set of ES and hence value all ES that help sustain their coffee production by buffering these climate change impacts and increase the resilience of their coffee production.

The provisional services (weed, food, timber, and fuel) were ranked second from last at all altitudes.
Figure 4 shows that within these provisional services rankings, food was preferred over weed at high altitude, and both were preferred over fuelwood and timber for high and mid altitude. For low altitude, these four ES were ranked equally important and relatively better than at high and mid altitudes. At high altitude and far away from markets, households rely much more on their own food production for autosufficiency and have less access to markets for timber, fuelwood and fruits compared to low altitude farmers closer to an urban demand. Therefore, it makes sense that food and weed were relatively more important at high altitudes, and that timber and fuelwood increased in relative importance at low altitude.

The consistent and significant low ranking of $P \& D$ is attributed to the lack of knowledge, as previously discussed. Still, farmers were able to rank CLR as significantly more important than WCSB at high altitude, probably because incidences of CLR have been found to be higher in unshaded systems which predominate at high altitude (Soto-Pinto et al. 2002).

Lastly, it has to be noted that mulch was the most preferred ES over all altitudes and in particular at high altitude. This preference could be explained by its multi-functionality. Mulch can provide a series of ES, such as soil moisture conservation, erosion control, yield improvement (through organic matter addition
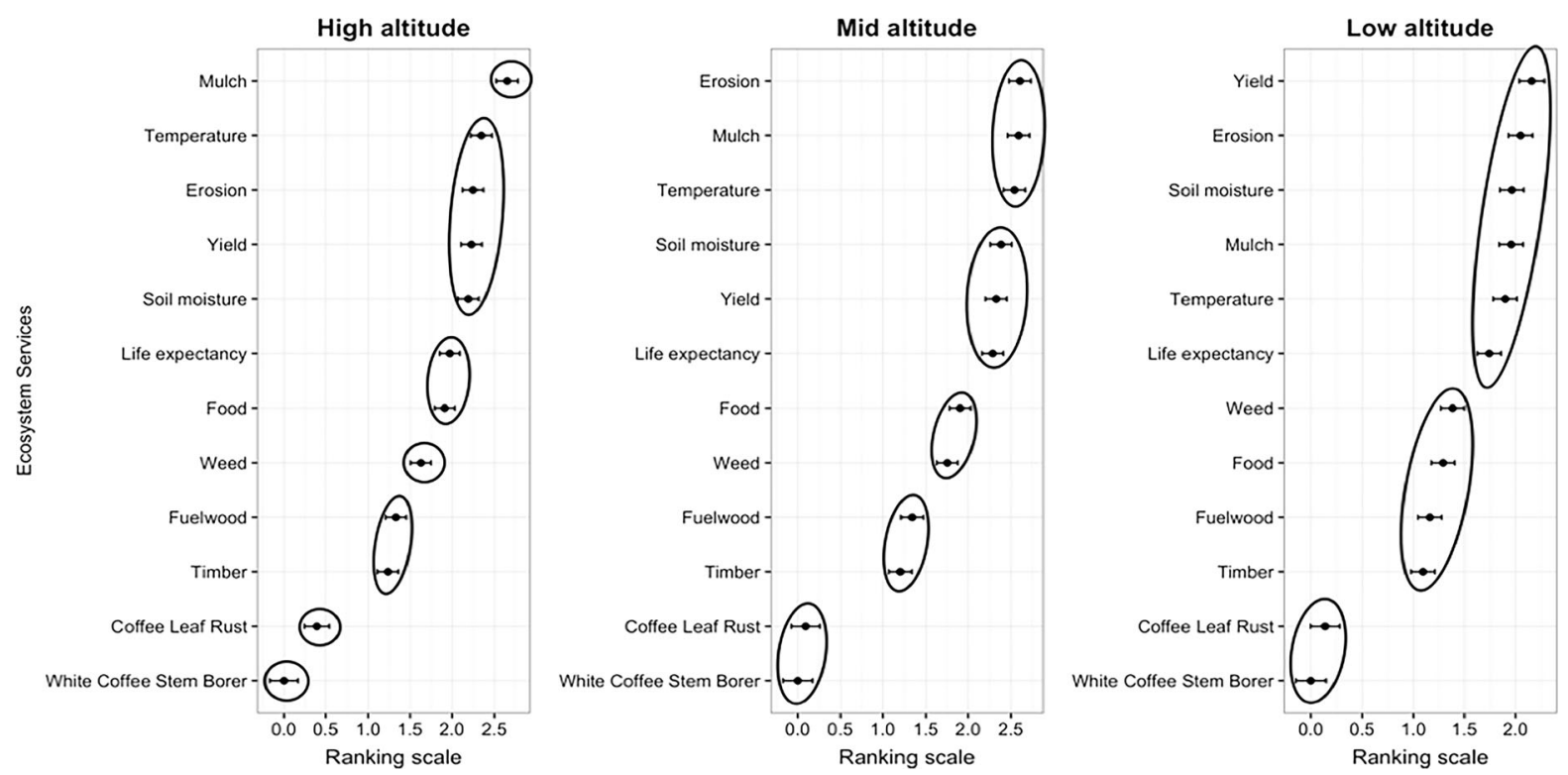

Fig. 4 Ranking of all ecosystem services (including controlling white coffee stem borer and coffee leaf rust) by altitude. Ranking estimates were grouped until the next ranking was significantly different from the first ranking of that group 
Fig. 5 The ecosystem services (ES) by altitude and by the subcategories or functions they are represented by. The first group of ES that were ranked highest and whose position was significantly different was labelled as ' high', the second significantly lower ranked group as 'medium' and the rest of the lower ranked ES as 'low'. WCSB and CLR stand for respectively White Coffee Stem Borer and Coffee Leaf Rust

\begin{tabular}{|c|c|c|c|c|c|}
\hline \multicolumn{2}{|l|}{ High } & \multirow{3}{*}{ Altitude zone $\rightarrow$} & \multirow{4}{*}{ High } & \multirow{4}{*}{ Mid } & \multirow{4}{*}{ Low } \\
\hline Medium & & & & & \\
\hline \multicolumn{2}{|l|}{ Low } & & & & \\
\hline ES category $\downarrow$ & ES subcategory $\downarrow$ & ES function $\downarrow$ & & & \\
\hline \multirow{4}{*}{ Regulating } & \multirow{2}{*}{ Soil fertility } & Mulch & & & \\
\hline & & Erosion & & & \\
\hline & \multirow{2}{*}{ Microclimate } & Temp & & & \\
\hline & & Soil moisture & & & \\
\hline \multirow{3}{*}{ Provisioning } & \multirow{2}{*}{ Coffee production } & Yield & & & \\
\hline & & Life expectancy & & & \\
\hline & Tree products & Food & & & \\
\hline Regulating & Weed control & Weed & & & \\
\hline \multirow{2}{*}{ Provisioning } & Tree products & Fuelwood & & & \\
\hline & Tree products & Timber & & & \\
\hline \multirow{2}{*}{ Regulating } & \multirow{2}{*}{ Pest and diseases } & CLR & & & \\
\hline & & WCSB & & & \\
\hline
\end{tabular}

and nutrient cycling) and weed control. At high altitude, compared to low altitude, the need for onfarm trees is lower because people harvest tree products from the nearby forest reserve (Chhetri et al. 2003). Hence, there are fewer trees providing canopy cover and mulching material, which could explain the relative importance of mulch as an ES at high altitude.

Tree species and ecosystem service rankings by gender

From interviews, men were found to be predominantly in charge of coffee management strategies and decision-making on ES and companion trees in coffee plots. However, the rankings between male and female preferences for ES provided by companion trees in the coffee plot at different altitudes did not show any differences (Fig. 6 for all altitudes combined). Still, slight permutations could be observed for erosion, yield, life expectancy and P\&D. Likewise for tree species, the rankings at different altitudes were similar between men and women as is illustrated for food and yield in Figs. 7 and 8 , for all altitudes combined. This was surprising since they were expected to be potentially genderspecific. Only small and negligible differences were observed (e.g. Albizia coriaria).
The absence of gender differences in ES preferences can be explained by the focus of this study on coffee plots and not on the whole farm that generally comprises plots with food crops for which women have more power on management decisions. The absence of gender differences in the tree species rankings, however, is an indication that local knowledge is not only ethnically and geographically blind (Sinclair and Joshi 2000), but also gender blind and therefore adding value to the use of local knowledge in agroforestry research and development.

Limitations of the study approach

The approach used in this study has the advantage that data collection is relatively quick and easy, the farmer's options by context are considered and recommendations can be readily made with the ranking results. However, some limitations have to be considered. First of all, the list of 12 ES is not exhaustive. It was decided to focus on those ES that were relevant to coffee farmers and as such taking into account climate change, food security and livelihood. However, an important ES not presently assessed, is shade quality in terms of light interception over the production cycle particularly. It is recommended to complement the current data base on a wider range of ES in further documentation of farmers' local 

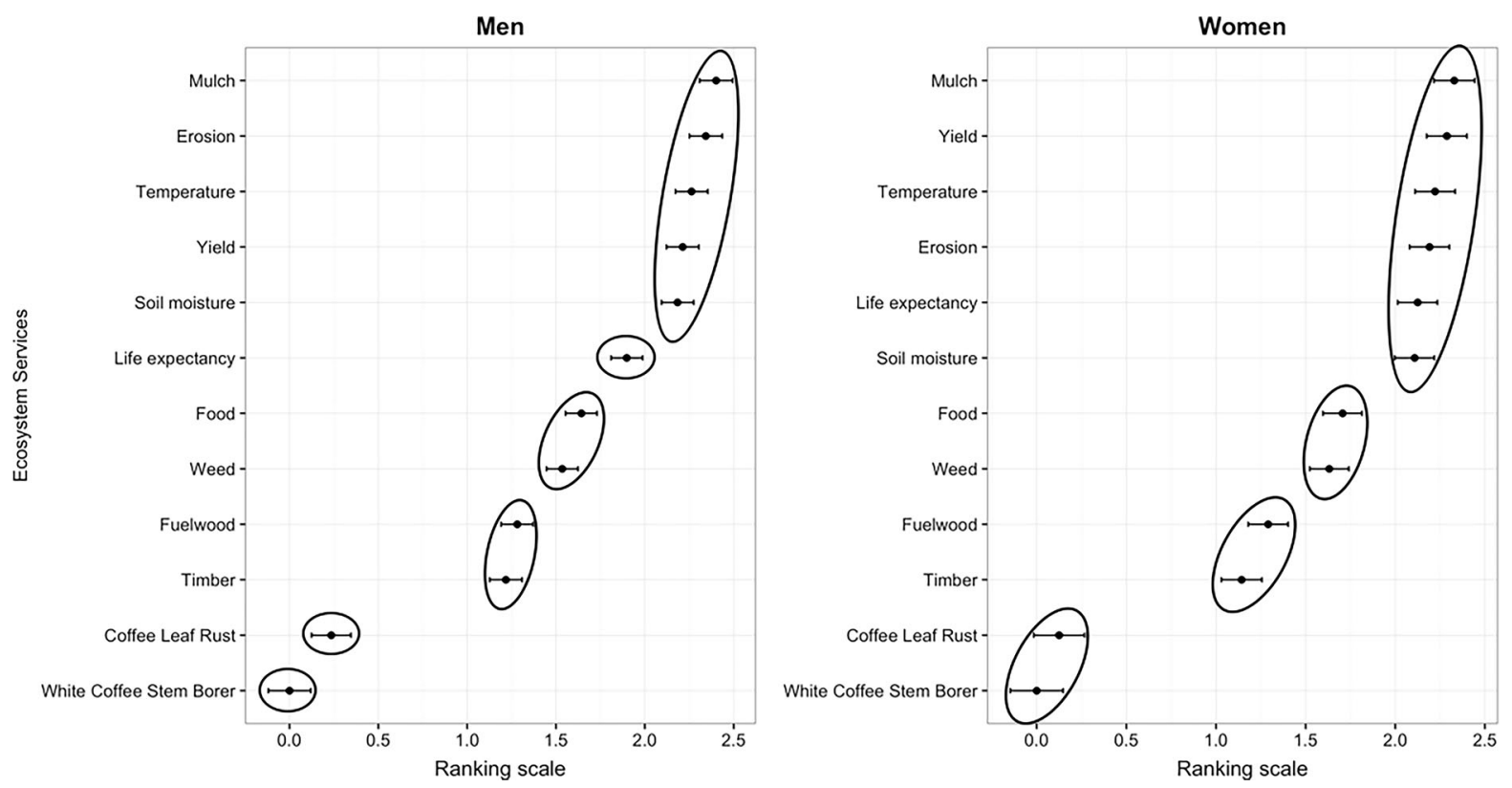

Fig. 6 Ranking of all ES by gender for all altitudes combined. The rankings were grouped until the next estimate was significantly different from the first ranking of that group
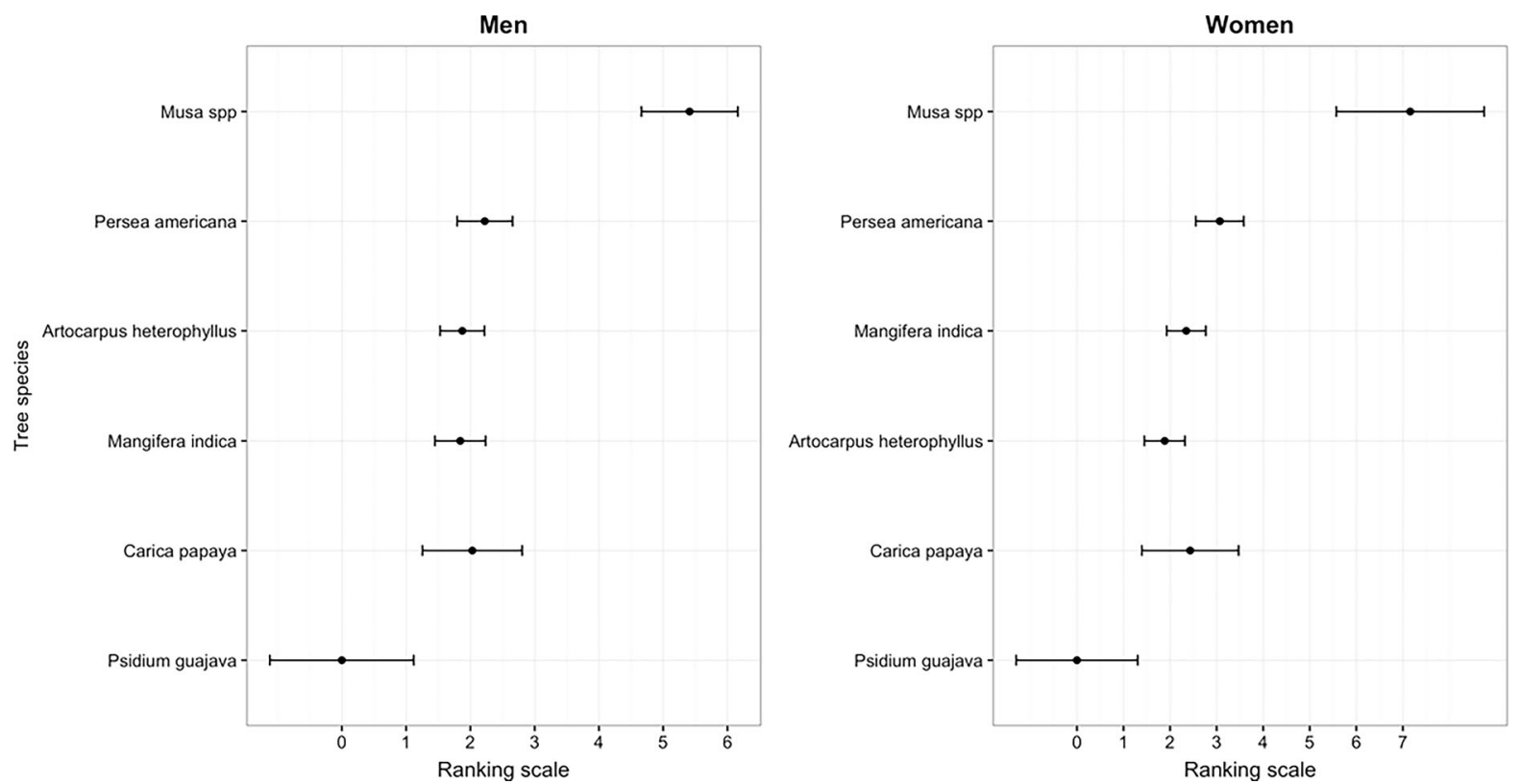

Fig. 7 Rankings of tree species for food provision by men and women separately and for all three altitudes combined

knowledge. Secondly, it has to be emphasised that the ranking results are relative and as such the ranking of individual species should always be considered in relation to the other species concurrently used in the ranking exercise. For instance, a low ranked species is not necessarily a bad species and could be higher ranked when considered in another context with a different set of species and ES. Thirdly, although local knowledge is site specific and takes into account livelihood for instance, it should be validated and used 

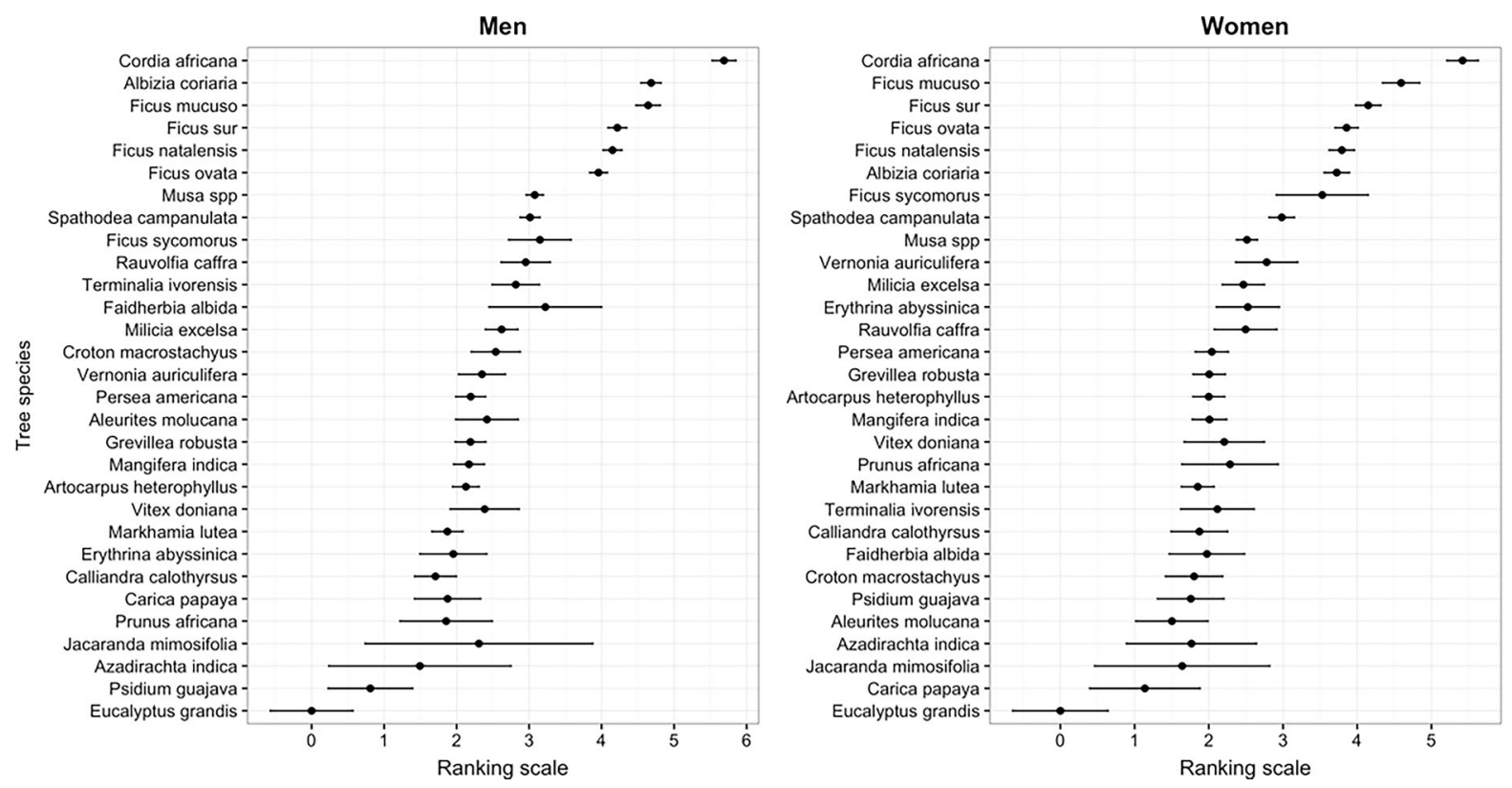

Fig. 8 Rankings of tree species for coffee yield improvement, by men and women separately, and for all three altitudes combined

complementary with expert knowledge of trees and their ES (Lamond et al. 2016; Smith-Dumont et al. in press; Van der Wolf et al. 2016). Furthermore, from a more holistic and realistic farmer's perspective, final recommendations by agricultural services have to take into account the biophysical and socio-economic contexts, both at farm and landscape level. As such research on local knowledge should also take into account not only the coffee plots, but the whole farm. Lastly, it is possible that the abundance of tree species influences the selection of trees and maybe to some extent their rankings. Locally abundant species are better known than rare ones and might therefore be selected and ranked by more farmers. Consequently, it is possible that unknown and non-abundant but potentially interesting species are ranked with more uncertainty or might even be left out of the analysis.

\section{Conclusion}

This paper describes how local knowledge can be used to rank tree species for a range of ES and rank those ES by the farmer's preference. These rankings can then be used in order to make recommendations for companion trees in coffee agroforestry systems along an altitudinal gradient that are tailored to the farmer's needs. Species can be categorised according to their capabilities for climate change adaptation, in terms of their capacity of providing ES under different climates. As farmers are increasingly experiencing difficulties growing Arabica coffee at low altitudes, they need a large set of ES that support their coffee production's resilience by e.g. contributing to soil fertility, microclimate, and coffee production. Despite the known impact of P\&D on coffee productivity and the potential $P \& D$ controlling services of companion trees, farmers lacked knowledge on how species affect P\&D dynamics. Moreover, it was expected that men and women would rank tree species and ES differently. However, the analysis showed that gender does not influence preferences and management decisions on companion species and the ES they provide, so it can be concluded that local knowledge is gender blind, adding value to its use in agroforestry research and development. A ranking approach has shown to be an appropriate and quick method for scientists to use local knowledge for the development of recommendation tools for coffee farmers and their associations. The ES preference rankings at each altitude are useful to understand the farmer's needs and their options by context since they inherently include site-specific and livelihood needs. Some limitations to the approach include the non-exhaustive list of ES and the relativity 
of the ranking results. The plot-level approach is especially useful if complemented by expert knowledge at farm and landscape level.

Acknowledgements This research was conducted under the CGIAR Research Program on Climate Change, Agriculture and Food Security (CCAFS) and under the Program Forestry, Trees and Agroforestry (FTA). The study was supported by the Federal Ministry for Economic Cooperation and Development of Germany (BMZ). The authors of this paper wish to show their appreciation and gratitude for Franco Manget and Wilberforce Wodada for their valuable assistance in the field, Theresa Liebig for her help with the baseline data collection and advice on pests and diseases, Dr. Richard Coe (ICRAF) for his advices on Bradley Terry ranking analysis in R, Allan Heinze for the ranking analysis functions in R, Jenny Ordonez (ICRAF) for her contribution to the methodology, Metajua for digitising the surveys, Ewaut Kissel for his significant help in R programming, and Mandy Malan for her daily support and endless reviews.

Open Access This article is distributed under the terms of the Creative Commons Attribution 4.0 International License (http:// creativecommons.org/licenses/by/4.0/), which permits unrestricted use, distribution, and reproduction in any medium, provided you give appropriate credit to the original author(s) and the source, provide a link to the Creative Commons license, and indicate if changes were made.

\section{References}

Albertin A, Nair PKR (2004) Farmers' perspectives on the role of shade trees in coffee production systems: an assessment from the Nicoya Peninsula, Costa Rica. Hum Ecol 32(4):443-463. doi:10.1023/B:HUEC.0000043515.84334. 76

Beer J, Muschler R, Kass D, Somarriba E (1998) Shade management in coffee and cacao plantations. Agrofor Syst 38:139-164. doi:10.1023/A:1005956528316

Bos MM, Steffan-Dewenter I, Tscharntke T (2007) Shade tree management affects fruit abortion, insect pests and pathogens of cacao. Agr Ecosyst Environ 120(2-4): 201-205. doi:10.1016/j.agee.2006.09.004

Bradley RA, Terry ME (1952) Rank analysis of incomplete block designs: the method of paired comparisons. Biometrika 39(3-4):324-345

Bunn C, Läderach P, Jimenez J, Montagnon C, Schilling T (2015a) Multiclass classification of agro-ecological zones for Arabica coffee: an improved understanding of the impacts of climate change. PLoS ONE. doi:10.1371/ journal.pone.0140490

Bunn C, Läderach P, Rivera OO, Kirschke D (2015b) A bitter cup: climate change profile of global production of Arabica and Robusta coffee. Clim Change 129:89-101. doi:10. 1007/s10584-014-1306-x

Campbell BM, Thornton P, Zougmoré R, Van Asten PJA, Lipper L (2014) Sustainable intensification: what is its role in climate smart agriculture? Curr Opin Environ Sustain 8:39-43. doi:10.1016/j.cosust.2014.07.002

Cerdán CR, Rebolledo MC, Soto G, Rapidel B, Sinclair FL (2012) Local knowledge of impacts of tree cover on ecosystem services in smallholder coffee production systems. Agric Syst 110:119-130. doi:10.1016/j.agsy.2012. 03.014

Chhetri P, Mugisha A, White S (2003) Community resource use in Kibale and Mt Elgon National Parks, Uganda. Parks 13(1):28-38

Chiputwa B, Spielman DJ, Qaim M (2015) Food standards, certification, and poverty among coffee farmers in Uganda. World Dev 66:400-412. doi:10.1016/j.worlddev.2014.09. 006

Craparo ACW, Van Asten PJA, Läderach P, Jassogne LTP, Grab SW (2015) Coffea arabica yields decline in Tanzania due to climate change: global implications. Agric For Meteorol 207:1-10. doi:10.1016/j.agrformet.2015.03.005

Davis AP, Gole TW, Baena S, Moat J (2012) The impact of climate change on indigenous arabica coffee (Coffea arabica): predicting future trends and identifying priorities. PLoS ONE 7(11):10-14. doi:10.1371/journal.pone.0047981

De Souza HN, de Goede RGM, Brussaard L, Cardoso IM, Duarte EMG, Fernandes RBA, Pulleman MM et al (2012) Protective shade, tree diversity and soil properties in coffee agroforestry systems in the Atlantic rainforest biome. Agr Ecosyst Environ 146(1):179-196. doi:10.1016/j.agee. 2011.11.007

Ellis F, Bahiigwa G (2003) Livelihoods and rural poverty reduction in Uganda. World Dev 31(6):997-1013. doi:10. 1016/S0305-750X(03)00043-3

Harvey C, Chacón M, Donatti CI, Garen E, Hannah L, Andrade A, Wollenberg E et al (2014) Climate-smart landscapes: opportunities and challenges for integrating adaptation and mitigation in tropical agriculture. Conserv Lett 7(2):77-90. doi:10.1111/conl.12066

Hijmans RJ, Cameron SE, Parra JL, Jones PG, Jarvis A (2005) Very high resolution interpolated climate surfaces for global land areas. Int J Climatol 25(15):1965-1978. doi:10. 1002/joc. 1276

Jaramillo J, Muchugu E, Vega FE, Davis A, Borgemeister C, Chabi-Olaye A (2011) Some like it hot: the influence and implications of climate change on coffee berry borer ( $\mathrm{Hy}$ pothenemus hampei) and coffee production in East Africa. PLoS ONE. doi:10.1371/journal.pone.0024528

Kasente D, Lockwood M, Vivian J, Whitehead A (2002) Gender and the expansion of non-traditional agricultural exports in Uganda. In: Razavi S (ed) shifting burdens: gender and agrarian change under neoliberalism. Kumarian Press, Bloomfield, pp 35-65

Kelemen E, Potschin M, Martín-López B, Pataki G (2015) Ecosystem services: a gender perspective. OpenNESS Ecosystem Service Reference Book

Kiptot E (2015) Gender roles, responsibilities, and spaces: implications for agroforestry research and development in Africa. Int For Rev 17(April):11-21. doi:10.1505/ 146554815816086426

Kiptot E, Franzel S, Degrande A (2014) Gender, agroforestry and food security in Africa. Curr Opin Environ Sustain 6(1):104-109. doi:10.1016/j.cosust.2013.10.019 
Läderach P, Oberthür T, Cook S, Estrada IM, Pohlan J, Fisher M, Rosales Lechuga R (2011) Systematic agronomic farm management for improved coffee quality. Field Crops Res 120(3):321-329. doi:10.1016/j.fcr.2010.10.006

Läderach P, Haggar J, Lau C, Eitzinger A, Ovalle O, Baca M, Lundy $\mathrm{M}$ et al (2013) Mesoamerican Coffee: building a climate change adaptation strategy. Int Center Trop Agric 2:1-4

Lamond G, Sandbrook L, Gassner A, Sinclair FL (2016) Local knowledge of tree attributes underpins species selection on coffee farms. Exp Agric. doi:10.1017/S0014479716000 168

Lecoutere E, Jassogne L (2016) "We're in this together": changing intra-household decision making for more cooperative smallholder farming. Universiteit Antwerpen, Institute of Development Policy and Management (IOB), Antwerp

Leemans R, de Groot RS (2003) Millennium Ecosystem Assessment: Ecosystems and human well-being: a framework for assessment. Island Press. http://library.wur.nl/ WebQuery/wurpubs/wever/326575

Liebig T, Jassogne L, Rahn E, Läderach P, Poehling H-M, Kucel $\mathrm{P}$ et al (2016) Towards a collaborative research: a case study on linking science to farmers' perceptions and knowledge on arabica coffee pests and diseases and its management. PLoS ONE 11(8):e0159392. doi:10.1371/ journal.pone.0159392

Mbogga MS (2012) Climate profiles and climate change vulnerability assessment for the Mbale region of Uganda

Meunier Q, Lemmens R, Morin A (2010) Alternatives to exotic species in Uganda: growth and cultivation of 85 indigenous trees. GraphiConsult (U) Ltd., Kampala

Ndenecho E, Lambi C (2010) Cameroon arid lands in transition: a case study of a fragile environment at the ante-room of desertification. J Appl Soc Sci 8(1\&2):141-154

Nzeyimana I, Hartemink AE, de Graaff J (2013) Coffee farming and soil management in Rwanda. Outlook Agric 42(1):47-52. doi:10.5367/oa.2013.0118

Orwa C, Mutua A, Kindt R, Jamnadass R, Anthony S (2009) Agroforestree database: a tree reference and selection guide version 4.0

Perfecto I, Armbrecht I, Philpott SM, Soto-Pinto L, Dietsch TV (2007) Shaded coffee and the stability of rainforest margins in northern Latin America. In: Tscharntke T, Leuschner C, Zeller M, Guhardja E, Bidin A (eds) Stability of tropical rainforest margins: linking ecological, economic and social constraints of land use and conservation. Springer, Berlin, pp 227-263

R Core Team (2015) A language and environment for statistical computing. R Foundation for Statistical Computing, Vienna

Rahn E, Läderach P, Baca M, Cressy C, Schroth G, Rikxoort H, Shriver J et al (2013) Climate change adaptation, mitigation and livelihood benefits in coffee production: where are the synergies? Mitig Adapt Strat Glob Change 19(8):1-19. doi:10.1007/s11027-013-9467-x

Sinclair FL, Joshi L (2000) Taking local knowledge about trees seriously. In: Lawrence A (ed) Forestry, forest users and research: new ways of learning. European Tropical Forest Research Network (ETFRN), Wageningen, pp 45-61
Smith-Dumont E, Lamond G, Nansamba R, Gassner A, Sinclair FL (in press) The utility of farmer ranking of tree attributes for selecting companion trees in coffee production systems. Agric Syst

Soto-Pinto L, Perfecto I, Caballero-Nieto J (2002) Shade over coffee: its effects on berry borer, leaf rust and spontaneous herbs in Chiapas, Mexico. Agrofor Syst 55(1):37-45. doi:10.1023/A:1020266709570

Soto-Pinto L, Villalvazo-López V, Jiménez-Ferrer G, RamírezMarcial N, Montoya G, Sinclair FL (2007) The role of local knowledge in determining shade composition of multistrata coffee systems in Chiapas, Mexico. Biodivers Conserv 16(2):419-436. doi:10.1007/s10531-005-5436-3

Staver C, Guharay F, Monterroso D, Muschler RG (2001) Designing pest-suppressive multistrata perennial crop systems: shade-grown coffee in central america. Agrofor Syst 53(2):151-170. doi:10.1023/A:1013372403359

Tscharntke T, Clough Y, Bhagwat S, Buchori D, Faust H, Hertel D, Wanger TC et al (2011) Multifunctional shade-tree management in tropical agroforestry landscapes: a review. J Appl Ecol 48(3):619-629. doi:10.1111/j.1365-2664. 2010.01939.x

Turner H, Firth D (2012) Bradley-Terry models in R: the BradleyTerry2 package. J Stat Softw 48(9):1-21

Uganda Bureau of Statistics (2016) The national population and housing census 2014: main report. Uganda Bureau of Statistics, Kampala

Vaast P, Kanten R, Siles P, Dzib B (2005) Shade: a key factor for coffee sustainability and quality. Conf Coffee 4:887-896

Vaast P, Bertrand B, Perriot JJ, Guyot B, Génard M (2006) Fruit thinning and shade improve bean characteristics and beverage quality of coffee (Coffea arabica L.) under optimal conditions. J Sci Food Agric 86(2):197-204. doi:10.1002/ jsfa. 2338

Valencia V, West P, Sterling EJ, García-Barrios L, Naeem S (2015) The use of farmers' knowledge in coffee agroforestry management: implications for the conservation of tree biodiversity. Ecosphere. doi:10.1890/ES14-00428.1

Van Asten PJA, Wairegi L, Bagamba F, Drew C (2010) Factors driving fertilizer adoption in banana (Musa spp.) systems in Uganda. Acta Hort 879:465-478

Van Asten PJA, Wairegi L, Mukasa D, Uringi N (2011) Agronomic and economic benefits of coffee-banana intercropping in Uganda's smallholder farming systems. Agric Syst 104(4):326-334. doi:10.1016/j.agsy.2010.12.004

Van Asten PJA, Wanyama I, Mukasa D, Nansamba R, Kisaakye J, Sserubiri I, Jassogne L et al (2012) Mapping and evaluating improved intercrop and soil management options for Ugandan coffee farmers. Technical report

Van der Wolf J, Jassogne L, Gram G, Vaast P (2016) Turning local knowledge on agroforestry into an online decisionsupport tool for tree selection in smallholders' farms. Exp Agric. doi:10.1017/S001447971600017X

Villamor GB, van Noordwijk M, Djanibekov U, Chiong-Javier ME, Catacutan D (2014) Gender differences in land-use decisions: shaping multifunctional landscapes? Curr Opin Environ Sustain 6(1):128-133. doi:10.1016/j.cosust.2013. 11.015

Wairegi L, van Asten PJA (2010) The agronomic and economic benefits of fertilizer and mulch use in highland banana 
systems in Uganda. Agric Syst 103(8):543-550. doi:10. 1016/j.agsy.2010.06.002

Wang N, Jassogne L, van Asten PJA, Mukasa D, Wanyama I, Kagezi G, Giller KE (2015) Evaluating coffee yield gaps and important biotic, abiotic, and management factors limiting coffee production in Uganda. Eur $\mathrm{J}$ Agron 63:1-11. doi:10.1016/j.eja.2014.11.003
World Conservation Monitoring Centre (1998a) Milicia excelsa. The IUCN Red List of Threatened Species 1998: e.T33903A9817388

World Conservation Monitoring Centre (1998b) Prunus africana. The IUCN Red List of Threatened Species 1998: e.T33631A9799059 